\title{
Clinical analysis of patients with respiratory failure after esophageal cancer operation
}

\author{
Jun Dong, Guo-Dong Wang, Hong-Zhi Wang \\ Key Laboratory of Carcinogenesis and Translational Research (Ministry of Education/Beijing), Intensive Care Unit, Peking University Cancer \\ Hospital \& Institute, Beijing, China \\ Contributions: (I) Conception and design: J Dong; (II) Administrative support: J Dong; (III) Provision of study materials or patients: J Dong; (IV) \\ Collection and assembly of data: GD Wang; (V) Data analysis and interpretation: GD Wang, HZ Wang; (VI) Manuscript writing: All authors; (VII) \\ Final approval of manuscript: All authors. \\ Correspondence to: Jun Dong. Department of Intensive Care Unit, Key Laboratory of Carcinogenesis and Translational Research (Ministry \\ of Education/Beijing), Peking University Cancer Hospital \& Institute, No. 52 of Fucheng Street, Haidian District, Beijing 100142, China. \\ Email: dongjun_djas@163.com.
}

Background: To explore the clinical profiles and outcomes of patients with acute respiratory failure (ARF) after esophagectomy.

Methods: We retrospectively analyzed cases of patients who had been diagnosed with ARF after esophagectomy and compared survivors with non-survivors to explore the risks that may affect their outcomes.

Results: In total, 62 patients were admitted to the intensive care unit (ICU) with ARF after esophagectomy between January 1, 2010, and December 31, 2017. Of these patients, 69.4\% needed mechanical ventilation, with an average time on the ventilator of 304 hours (304.33 \pm 374.37 hours). The average length of stay in the ICU and in the hospital were 14 days (14.48 \pm 17.64 days) and 50 days ( $50.15 \pm 37.28$ days), respectively. Mortality in the ICU and 90 days after the operation was $6.5 \%$ and $16.1 \%$, respectively. Compared with the survivors, the 90-day post-operative non-survivors had a poorer $\mathrm{N}$ stage in the TNM classification system. The causes of ARF included anastomotic leakage, pneumonia, vocal cord paralysis, sputum plugging, pulmonary embolism (PE), and acute respiratory distress syndrome (ARDS). ARF induced by different factors occurred at different times and had different outcomes. The three most common reasons for mortality in the ICU were ARDS (33.33\%), anastomotic leakage (11.76\%), and pneumonia (10\%). The three most common reasons for mortality in the 90-day post-operative period were pneumonia (40\%), anastomotic leakage (23.53\%), and ARDS and acute exacerbations of chronic obstructive pulmonary disease (AECOPD) (33.33\%).

Conclusions: Anastomotic leakage, pneumonia, ARDS, and AECOPD were the main causes of death in ARF patients after esophagectomy. We found that the N stage in the TNM classification system may affect 90-day post-operative mortality in these patients.

Keywords: Acute respiratory failure (ARF); esophagectomy; TNM stage; anastomotic leakage

Submitted Aug 03, 2021. Accepted for publication Nov 04, 2021.

doi: $10.21037 /$ tcr-21-1505

View this article at: https://dx.doi.org/10.21037/tcr-21-1505

\section{Introduction}

Esophageal cancer is the ninth most common cancer worldwide (1). At the same time, it is the sixth leading cause of cancer-related mortality worldwide because of its high malignant potential and poor prognosis (2). For most patients without distant metastases, esophagectomy is still the mainstay of cancer treatment with or without chemoradiotherapy (3). Surgical resection of the esophagus offers curative potential, but the procedure is technically difficult. This highly invasive procedure is often followed 
by several serious postoperative complications, especially acute respiratory failure (ARF). ARF is the main cause of mortality in these post-operative patients (4). We analyzed 62 cases of patients who had ARF complications after esophagectomy to investigate the causes of ARF and the factors that influence survival and to provide evidence for precautions that could be taken to avoid respiratory failure after esophagectomy.

We present the following article in accordance with the STROBE reporting checklist (available at https://dx.doi. org/10.21037/tcr-21-1505).

\section{Methods}

\section{Patients}

From January 1, 2010, to December 31, 2017, patients who had undergone esophagectomy for esophageal cancer at the Peking University Cancer Hospital were retrospectively screened. Patients admitted to the intensive care unit (ICU) suffering from ARF after esophagectomy were included in our study. ARF is defined as an inadequate exchange of oxygen and carbon dioxide. It is diagnosed when the exchange does not meet metabolic needs, leading to hypoxemia with or without hypercapnia. An arterial blood gas measurement provides the basis of the diagnosis; when the partial pressure of oxygen $\left(\mathrm{PaO}_{2}\right)$ falls below $60 \mathrm{mmHg}$ and/or the partial pressure of carbon dioxide exceeds $50 \mathrm{mmHg}$ at sea level [fraction of inspired oxygen $\left(\mathrm{FIO}_{2}\right)$ of 0.21 ], gas exchange is clearly inadequate (5). The study was conducted in accordance with the Declaration of Helsinki (as revised in 2013). The study was approved by Ethics Committee of Peking University Cancer Hospital \& Institute and individual consent for this retrospective analysis was waived.

Patient variables, including demography, the TNM stage of their esophageal cancer, underlying diseases, and biomarkers, were collected according to historical electronic medical records. We also collected their operation details, including the time of the operation, fluid balance, and the time of one-lung ventilation. The cause of ARF, including anastomotic leakage, pneumonia, vocal codes paralysis, sputum plugging, pulmonary embolism, acute respiratory distress syndrome, acute exacerbations of chronic obstructive pulmonary disease, delay of recovery, atelectasis, Guillain-Barre Syndrome, phrenic nerve injury, acute heart failure were collected. Pneumonia was defined in the 2005 document as the presence of "new lung infiltrate plus clinical evidence that the infiltrate is of an infectious origin, which include the new onset of fever, purulent sputum, leukocytosis, and decline in oxygenation (6). The vocal codes paralysis was defined as the patient had difficulty in phonation and breathing. Laryngoscope or fiberoptic bronchoscope showed bilateral vocal cords and was placed in the midline with poor movement. The ARDS was according to the Berlin definition of ARDS (7).

We also collected the APACHE II score on admission to the ICU, the time of the onset of ARF after the operation, the causes of ARF, and mortality in the ICU and 90 days after the operation.

\section{Statistical methods}

Data were analyzed using IBM's SPSS, version 20. Qualitative variables were expressed as a number and percentage and were compared using the chi-square test. In addition, quantitative variables were expressed as mean \pm standard deviation and were compared using the Student's $t$-test. The difference between variables was considered statistically significant when the $\mathrm{P}$ value was $\leq 0.05$.

\section{Results}

From January 1, 2010, to December 31, 2017, 1,872 patients who underwent esophagectomy for the treatment of esophageal cancer at the Peking University Cancer Hospital were screened retrospectively. Of these, 62 patients admitted to the ICU because of ARF after esophagectomy were included in our study.

In our study, patients had a mean age of 63 years $(63.35 \pm 7.55$ years $)$, and $12.9 \%(8 / 62)$ were female. Overall, $69.4 \%(43 / 62)$ of the patients needed mechanical ventilation, the average time on the ventilator was 304 hours $(304.33 \pm 374.37$ hours), the average length of stay in the ICU was 14 days $(14.48 \pm 17.64$ days), mortality in the ICU was $6.5 \%$ (4/62), and the average length of stay in the hospital was 50 days $(50.15 \pm 37.28$ days). Ninety-day mortality was $16.1 \%(10 / 62)$.

The causes of ARF in these 62 patients are listed in Table 1 below. Anastomotic leakage was the primary cause of mortality both in the ICU and 90 days after the operation.

The time of occurrence of ARF varied from within 24 hours to more than 15 days after the operation. Within 24 hours, the main causes of ARF were vocal cord paralysis $(40 \%, 6 / 15)$ and delayed recovery from anesthesia $(20 \%, 3 / 15)$. As time progressed, the rate of anastomotic 
Table 1 Reasons to ARF after esophagectomy

\begin{tabular}{lccc}
\hline Cause & Cases & Mortality in ICU & Mortality within 90 days \\
\hline Anastomotic leakage & 17 & $11.76 \%(\mathrm{n}=2)$ & $23.53 \%(\mathrm{n}=4)$ \\
Pneumonia & 9 & $10.00 \%(\mathrm{n}=1)$ & $40.00 \%(\mathrm{n}=4)$ \\
Vocal cords paralysis & 7 & $0.00 \%$ & $0.00 \%$ \\
Sputum plugging & 7 & $0.00 \%$ & $0.00 \%$ \\
PE & 4 & $0.00 \%$ & $0.00 \%$ \\
ARDS & 3 & $33.33 \%(\mathrm{n}=1)$ & $33.33 \%(\mathrm{n}=1)$ \\
AECOPD & 3 & $0.00 \%$ & $33.33 \%(\mathrm{n}=1)$ \\
Delay of recovery & 3 & $0.00 \%$ & $0.00 \%$ \\
Atelectasis & 3 & $0.00 \%$ & $0.00 \%$ \\
GB Syndrome & 2 & $0.00 \%$ & $0.00 \%$ \\
Phrenic nerve injury & 2 & $0.00 \%$ & $0.00 \%$ \\
AHF & 2 & $0.00 \%$ & $0.00 \%$ \\
Total & 62 & $6.45 \%(\mathrm{n}=4)$ & $16.13 \%(\mathrm{n}=10)$ \\
\hline ARF, acute respiratory & \\
\hline
\end{tabular}

ARF, acute respiratory failure; PE, Pulmonary embolism; ARDS, acute respiratory distress syndrome; AECOPD, acute exacerbations of chronic obstructive pulmonary disease; GB Syndrome, Guillain-Barre Syndrome; AHF, acute heart failure.

leakage increased; it was at nearly $60 \%(4 / 7)$ when ARF occurred more than 15 days after the operation (Figure 1).

We also analyzed factors such as the TNM stage of esophageal cancer, underlying diseases, and biomarkers in these ARF patients to evaluate if they affected mortality. We found that the lymph node stage (L) might affect the 90-day mortality. Apart from this, there were no other factors that showed a statistically significant difference between the survivors and non-survivors (Table 2).

There were no significant differences between the ARF patients during the operation (Table 3). Understandably, the non-survivors were more seriously ill than the survivors on admission to the ICU (Table 4).

\section{Discussion}

Esophagectomy is a highly invasive procedure with several serious post-operative complications, including pneumonia, anastomotic leakage, and recurrent laryngeal nerve paralysis, which may result in ARF or even multi-organ failure $(8,9)$. In our study, the top three causes of ARF were anastomotic leakage, pneumonia, vocal cord paralysis, and sputum plugging. Anastomotic leakage and pneumonia were not only the main causes of ARF but also of mortality in the ICU and 90 days after the operation. As is well understood, the different causes of ARF significantly influence longterm survival. In this respect, ARF patients who developed anastomotic leakage and pneumonia had a significantly higher risk of a poor outcome, while ARF patients with vocal cord paralysis and sputum plugging were more likely to have a good outcome. This is consistent with previous studies (10).

The results in Figure 1 show that the causes of ARF within 24 hours of the operation mainly consisted of delayed recovery from anesthesia, vocal cord paralysis, and sputum plugging. The reason that delayed recovery from anesthesia is a cause of ARF is clear. To counter this, we can use an antagonist to the anesthetic until the patient is awake. In terms of vocal cord paralysis, this is caused by the recurrent laryngeal nerve (RLN) being injured during esophagectomy, especially McKeown esophagectomy. To avoid this, surgeons should take extra care or use a special trachea cannula that can monitor the RLN using an electrode. The reason that sputum plugging is considered a cause of ARF is because these patients are too weak to clear sputum or the cough/gag reflex is absent. Timing of the onset of ARF varied from less than 24 hours to 4 days after the operation. Thus, we should constantly monitor the airway, help patients with breathing exercises, and facilitate the clearing of sputum. If necessary, we should use a fiber tracheoscope 


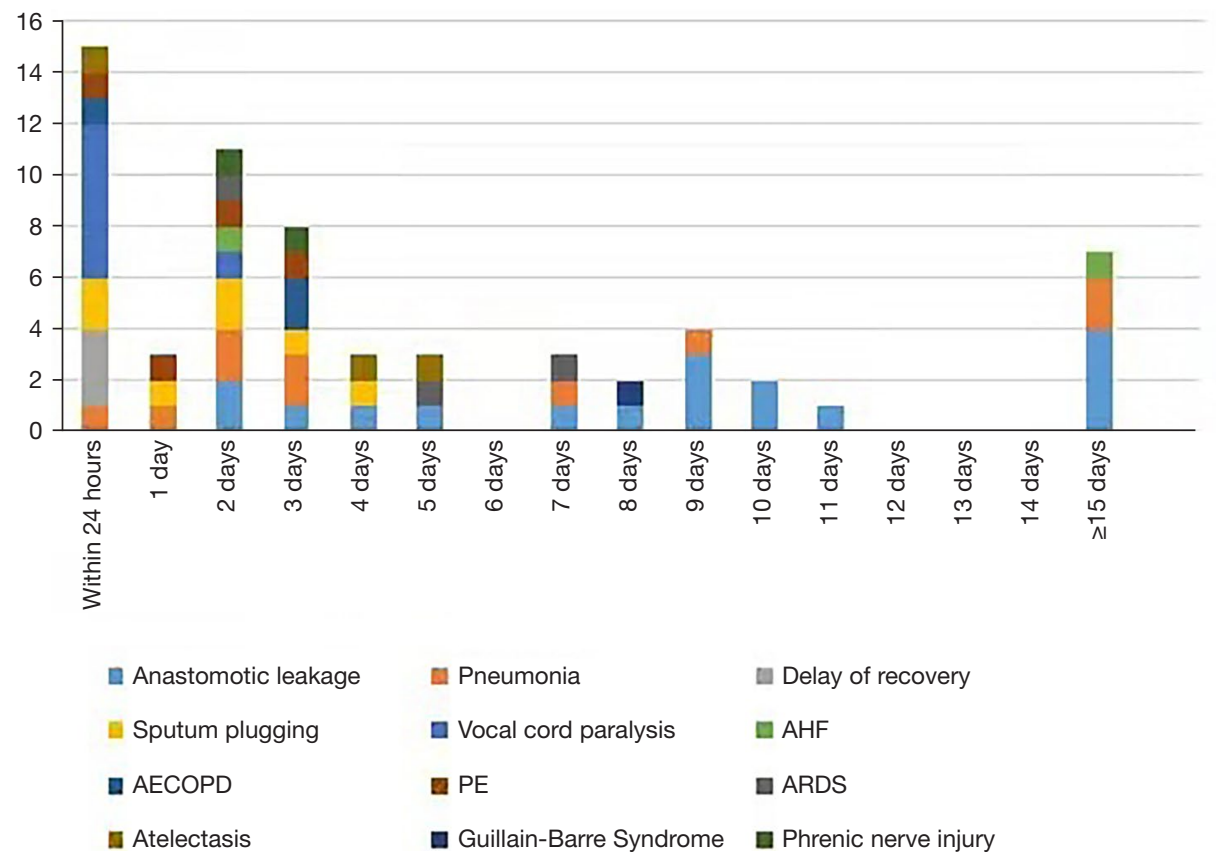

Figure $1 \mathrm{ARF}$ time distribution. ARF, acute respiratory failure; PE, pulmonary embolism; ARDS, acute respiratory distress syndrome; AECOPD, acute exacerbations of chronic obstructive pulmonary disease; AHF, acute heart failure.

to aspirate the sputum. Delayed recovery from anesthesia, vocal cord paralysis, and sputum plugging cause ARF by obstructing the upper airway. To treat this, we need to open the airway immediately, including the oropharyngeal airway, suction the sputum, and apply tracheal intubation. Patients with delayed recovery from anesthesia, vocal cord paralysis, and sputum plugging that receive these treatments always have a good outcome without any remaining sequelae.

In the case of patients who suffer from ARF several days after the operation, we should consider whether there are likely to be serious complications, such as thorax infection, pneumonia, and pulmonary thromboembolism (PE). Thorax infection, which can be caused by anastomotic leakage, is of particular concern. Anastomotic leakage can be diagnosed using water-soluble contrast swallow, a computed tomography scan, gastroscopy, or bronchoscopy. It is difficult and expensive to cure thorax infections caused by anastomotic leakage. ARF patients with anastomotic leakage had higher mortality than other patients. To treat these patients, apart from using antibiotics, sufficient drainage, and providing nutritional support, surgical intervention may be necessary. In addition, PE needs to be considered. Computer tomography pulmonary angiography is helpful in diagnosing PE. To prevent it, we can administer heparin or low molecular weight heparin in patients with a low risk of bleeding.

In this study, we compared the differences in the patient's demography, comorbidity, and organ functions, as well as other factors, between the survivors and non-survivors. We found only the N stage in the TNM classification to be statistically significant in relation to 90-day mortality between the two groups. Previous studies achieved similar results. The number of regional lymph nodes containing metastases is the most important prognostic factor in patients undergoing resection for esophageal cancer (11). We could not demonstrate any character association between the survivors and non-survivors perioperation, indicating that preoperative identification of patients at high ARF risk is difficult. Sachdev et al. noted that there are some ARF risk factors after almost all kinds of surgery. But in terms of esophagectomy, they demonstrated that the evidence, which were of poor quality or were conflicted, were hard to determine whether the factors increase the risk or whether the laboratory tests predicting risk (12).

Finally, in our study, the total number of cases of ARF after esophagectomy was about $3.3 \%(62 / 1,872)$. This is much lower than in previous studies, which had figures of $33-38 \%(13,14)$. The possible reason for this is that, in our study, we enrolled ARF patients who had been transferred to the ICU, but all were ARF patients. Some ARF patients, 
Table 2 Differences between survivors with non-survivors before operation

\begin{tabular}{|c|c|c|c|c|c|c|}
\hline Characteristic & \multicolumn{3}{|c|}{ Mortality in ICU } & \multicolumn{3}{|c|}{ 90-day mortality } \\
\hline Age (year) & $61.50 \pm 6.19$ & $63.48 \pm 7.66$ & 0.615 & $63 \pm 5.14$ & $63.42 \pm 7.96$ & 0.873 \\
\hline Gender & & & 0.433 & & & 0.382 \\
\hline Male & $75 \%(n=3)$ & $87.9 \%(n=51)$ & & $80 \%(n=8)$ & $88.5 \%(n=46)$ & \\
\hline BMI $\left(\mathrm{kg} / \mathrm{m}^{2}\right)$ & $22.98 \pm 2.80$ & $23.75 \pm 3.79$ & 0.692 & $22.62 \pm 2.73$ & $23.90 \pm 3.87$ & 0.323 \\
\hline \multicolumn{7}{|l|}{ TNM stage } \\
\hline $\mathrm{T}$ & & & 0.644 & & & 0.839 \\
\hline 0 & 0 & $3.4 \%(n=2)$ & & 0 & $3.8 \%(n=2)$ & \\
\hline 3 & $50 \%(n=2)$ & $48.3 \%(n=28)$ & & $40 \%(n=4)$ & $50 \%(n=26)$ & \\
\hline 4 & 0 & $6.9 \%(n=4)$ & & $10 \%(n=1)$ & $5.8 \%(n=3)$ & \\
\hline$x$ & 0 & $1.7 \%(n=1)$ & & 0 & $1.9 \%(n=1)$ & \\
\hline $\mathrm{N}$ & & & 0.103 & & & \\
\hline 0 & $25 \%(n=1)$ & $70.7 \%(n=41)$ & & $30 \%(n=3)$ & $75 \%(n=39)$ & \\
\hline 1 & $50 \%(n=2)$ & $15.5 \%(n=9)$ & & $30 \%(n=3)$ & $15.4 \%(n=8)$ & \\
\hline 2 & 0 & $6.9 \%(n=4)$ & & 0 & $7.7 \%(n=4)$ & \\
\hline 3 & $25 \%(n=1)$ & $6.9 \%(n=4)$ & & $40 \%(n=4)$ & $1.9 \%(n=1)$ & \\
\hline Smoking history & & & 0.728 & & & 0.507 \\
\hline Yes & $75 \%(n=3)$ & $74.1 \%(n=43)$ & & $70 \%(n=7)$ & $75 \%(n=39)$ & \\
\hline No & $25 \%(n=1)$ & $25.9 \%(n=15)$ & & $30 \%(n=3)$ & $25 \%(n=13)$ & \\
\hline Drinking history & & & 0.411 & & & 0.279 \\
\hline Yes & $75 \%(n=3)$ & $55.2 \%(n=32)$ & & $70 \%(n=7)$ & $53.8 \%(n=28)$ & \\
\hline No & $25 \%(n=1)$ & $44.8 \%(n=26)$ & & $30 \%(n=3)$ & $46.2 \%(n=24)$ & \\
\hline Chemotherapy before operation & & & 0.533 & & & 0.634 \\
\hline Yes & $50 \%(n=2)$ & $39.7 \%(n=23)$ & & $40 \%(n=4)$ & $40.4 \%(n=21)$ & \\
\hline No & $50 \%(n=2)$ & $60.3 \%(n=35)$ & & $60 \%(n=6)$ & $59.6 \%(n=31)$ & \\
\hline
\end{tabular}

Table 2 (continued) 
Table 2 (continued)

\begin{tabular}{|c|c|c|c|c|c|c|}
\hline Characteristic & \multicolumn{3}{|c|}{ Mortality in ICU } & \multicolumn{3}{|c|}{ 90-day mortality } \\
\hline Hypertension & & & 0.553 & & & 0.229 \\
\hline Yes & $25 \%(n=1)$ & $36.2 \%(n=21)$ & & $20 \%(n=2)$ & $38.5 \%(n=20)$ & \\
\hline No & $75 \%(n=3)$ & $63.8 \%(n=37)$ & & $80 \%(n=8)$ & $61.5 \%(n=32)$ & \\
\hline Yes & $25 \%(n=1)$ & $8.6 \%(n=5)$ & & $20 \%(n=2)$ & $7.7 \%(n=4)$ & \\
\hline No & $75 \%(n=3)$ & $91.4 \%(n=53)$ & & $80 \%(n=8)$ & $92.3 \%(n=48)$ & \\
\hline $\mathrm{CHD}$ & & & 0.816 & & & 0.584 \\
\hline Yes & 0 & $5.2 \%(n=3)$ & & 0 & $5.8 \%(n=3)$ & \\
\hline WBC $\left(\times 10^{9} / \mathrm{L}\right)$ & $5.85 \pm 1.82$ & $6.67 \pm 2.66$ & 0.548 & $6.00 \pm 1.33$ & $6.74 \pm 2.79$ & 0.421 \\
\hline HGB (g/L) & $142.75 \pm 23.81$ & $138.62 \pm 18.35$ & 0.670 & $141.2 \pm 27.80$ & $138.44 \pm 16.53$ & 0.670 \\
\hline PLT (×10/L) & $223.5 \pm 79.66$ & $209.79 \pm 62.96$ & 0.680 & $201 \pm 73.70$ & $212.54 \pm 61.94$ & 0.603 \\
\hline AST (IU/L) & $20.25 \pm 5.12$ & $21.83 \pm 6.01$ & 0.611 & $20.0 \pm 3.56$ & $22.06 \pm 6.25$ & 0.319 \\
\hline ALT (IU/L) & $17.00 \pm 2.00$ & $16.90 \pm 9.28$ & 0.982 & $16.50 \pm 5.38$ & $16.98 \pm 9.55$ & 0.878 \\
\hline TBIL $(\mu \mathrm{mol} / \mathrm{L})$ & $13.40 \pm 6.21$ & $16.33 \pm 20.00$ & 0.773 & $29.53 \pm 45.39$ & $13.40 \pm 4.69$ & 0.290 \\
\hline $\mathrm{DBIL}(\mu \mathrm{mol} / \mathrm{L})$ & $4.78 \pm 2.12$ & $6.11 \pm 18.71$ & 0.888 & $18.04 \pm 43.59$ & $3.57 \pm 1.22$ & 0.321 \\
\hline $\mathrm{TP}(\mathrm{g} / \mathrm{L})$ & $73.48 \pm 4.29$ & $70.96 \pm 7.06$ & 0.487 & $71.13 \pm 8.66$ & $71.12 \pm 6.61$ & 0.999 \\
\hline Yes & $33.3 \%(n=1)$ & $76.5 \%(n=39)$ & & $50 \%(n=4)$ & $78.3 \%(n=36)$ & \\
\hline No & $66.7 \%(n=2)$ & $23.5 \%(n=12)$ & & $50 \%(n=4)$ & $21.7 \%(n=10)$ & \\
\hline Diffusion function impaired & & & 0.534 & & & 0.17 \\
\hline Yes & 0 & $19.6 \%(n=10)$ & & $100 \%(n=8)$ & $78.3 \%(n=36)$ & \\
\hline No & $100 \%(n=3)$ & $80.4 \%(n=41)$ & & 0 & $21.7 \%(n=10)$ & \\
\hline \multicolumn{7}{|l|}{ Echocardiography } \\
\hline LVEF & $61.00 \pm 1.41$ & $65.93 \pm 5.54$ & 0.220 & $64.67 \pm 4.84$ & $65.88 \pm 5.65$ & 0.622 \\
\hline$E / A \geq 1$ & $100 \%(n=1)$ & $35.7 \%(n=15)$ & 0.372 & $60 \%(n=3)$ & $34.2 \%(n=13)$ & 0.260 \\
\hline$E / A<1$ & 0 & $64.3 \%(n=27)$ & & $40.0 \%(n=2)$ & $65.8 \%(n=25)$ & \\
\hline
\end{tabular}

DM, diabetes mellitus; CHD, coronary heart disease; LVEF, left ventricular ejection fraction; E/A, E wave A wave ratio. 
Table 3 Differences between survivors with non-survivors during operation

\begin{tabular}{|c|c|c|c|c|c|c|}
\hline Operation characteristic & \multicolumn{3}{|c|}{ Mortality in ICU } & \multicolumn{3}{|c|}{ 90-day mortality } \\
\hline Operation & & & 1.000 & & & 1.000 \\
\hline McKeown & $75 \%(n=3)$ & $60.3 \%(n=35)$ & & $60 \%(n=6)$ & $61.5 \%(n=32)$ & \\
\hline Ivor-Lewis operation & $25 \%(n=1)$ & $36.2 \%(n=21)$ & & $40 \%(n=4)$ & $34.6 \%(n=18)$ & \\
\hline Operation time (min) & $312.50 \pm 132.00$ & $342.84 \pm 100.94$ & 0.570 & $343.00 \pm 134.42$ & $340.48 \pm 96.38$ & 0.944 \\
\hline \multicolumn{7}{|l|}{ Fluid } \\
\hline Colloidal fluid $(\mathrm{mL})$ & $1,125.00 \pm 250.00$ & $1,022.41 \pm 380.69$ & 0.599 & $1,200.00 \pm 483.05$ & $996.15 \pm 344.12$ & 0.114 \\
\hline Crystalloid fluid (mL) & $1,925.00 \pm 722.84$ & $2,163.79 \pm 579.08$ & 0.435 & $2,095.00 \pm 506.87$ & $2,158.65 \pm 603.07$ & 0.756 \\
\hline Blood loss (mL) & $245.00 \pm 136.99$ & $201.72 \pm 142.95$ & 0.560 & $248.00 \pm 220.19$ & $196.15 \pm 122.81$ & 0.294 \\
\hline
\end{tabular}

Table 4 Patients severity

\begin{tabular}{|c|c|c|c|c|c|c|}
\hline Patients severity & \multicolumn{3}{|c|}{ Mortality in ICU } & \multicolumn{3}{|c|}{ 90-day mortality } \\
\hline Lactic acid clearance rate (\%) & $38.58 \pm 40.69$ & $26.20 \pm 39.37$ & 0.545 & $33.89 \pm 29.52$ & $225.68 \pm 40.83$ & 0.463 \\
\hline Organ dysfunction & & & 0.011 & & & 0.002 \\
\hline Yes & $100 \%(n=4)$ & $29.3 \%(n=17)$ & & $80 \%(n=8)$ & $25 \%(n=13)$ & \\
\hline APACHE II score & $20.75 \pm 7.50$ & $14.72 \pm 6.27$ & 0.071 & $19.60 \pm 8.62$ & $14.25 \pm 5.66$ & 0.015 \\
\hline
\end{tabular}

especially those with mild symptoms, remained on the wards.

Several limitations should be mentioned. First, this study was a retrospective study. A prospective study with a control group consisting of patients without ARF may be more useful. Second, some data were missing, especially data regarding ultrasound cardiogram and lung function. Third, the sample size in our study was small, thus increasing the risk of a type 2 error due to a lack of statistical power. Larger studies are needed to address the challenging issues arising during the treatment of ARF patients after esophagectomy.

\section{Conclusions}

$\mathrm{ARF}$ is a severe complication after esophagectomy. But
ARF caused by different institutions will have different outcomes. Anastomotic leakage, pneumonia, ARDS and AECOPD were the main causes of death in ARF patients after esophagectomy. We found the $\mathrm{N}$ stage of the TNM classification to be statistically significant in relation to the difference between survivors and non-survivors.

\section{Acknowledgments}

We would like to acknowledge Kim Huggens for language editing.

Funding: None.

\section{Footnote}

Reporting Checklist: The authors have completed the 
STROBE reporting checklist. Available at https://dx.doi. org/10.21037/tcr-21-1505

Data Sharing Statement: Available at https://dx.doi. org/10.21037/tcr-21-1505

Conflicts of Interest: All authors have completed the ICMJE uniform disclosure form (available at https://dx.doi. org/10.21037/tcr-21-1505). The authors have no conflicts of interest to declare.

Ethical Statement: The authors are accountable for all aspects of the work in ensuring that questions related to the accuracy or integrity of any part of the work are appropriately investigated and resolved. The study was conducted in accordance with the Declaration of Helsinki (as revised in 2013). The study was approved by Ethics Committee of Peking University Cancer Hospital \& Institute and individual consent for this retrospective analysis was waived.

Open Access Statement: This is an Open Access article distributed in accordance with the Creative Commons Attribution-NonCommercial-NoDerivs 4.0 International License (CC BY-NC-ND 4.0), which permits the noncommercial replication and distribution of the article with the strict proviso that no changes or edits are made and the original work is properly cited (including links to both the formal publication through the relevant DOI and the license). See: https://creativecommons.org/licenses/by-nc-nd/4.0/.

\section{References}

1. Lagergren J, Smyth E, Cunningham D, et al. Oesophageal cancer. Lancet 2017;390:2383-96.

2. Jemal A, Bray F, Center MM, et al. Global cancer statistics. CA Cancer J Clin 2011;61:69-90.

3. Cooper JS, Guo MD, Herskovic A, et al. Chemoradiotherapy of locally advanced esophageal cancer: long-term follow-up of a prospective randomized trial (RTOG 85-01). Radiation Therapy Oncology Group. JAMA 1999;281:1623-7.

Cite this article as: Dong J, Wang GD, Wang HZ. Clinical analysis of patients with respiratory failure after esophageal cancer operation. Transl Cancer Res 2021;10(12):5238-5245. doi: $10.21037 /$ tcr-21-1505
4. Booka E, Takeuchi H, Nishi T, et al. The Impact of Postoperative Complications on Survivals After Esophagectomy for Esophageal Cancer. Medicine (Baltimore) 2015;94:e1369.

5. Canet J, Gallart L. Postoperative respiratory failure: pathogenesis, prediction, and prevention. Curr Opin Crit Care 2014;20:56-62.

6. American Thoracic Society; Infectious Diseases Society of America. Guidelines for the management of adults with hospital-acquired, ventilator-associated, and healthcareassociated pneumonia. Am J Respir Crit Care Med 2005;171:388-416.

7. ARDS Definition Task Force; Ranieri VM, Rubenfeld GD, et al. Acute respiratory distress syndrome: the Berlin Definition. JAMA 2012;307:2526-33.

8. Kinugasa S, Tachibana $M$, Yoshimura H, et al. Postoperative pulmonary complications are associated with worse short- and long-term outcomes after extended esophagectomy. J Surg Oncol 2004;88:71-7.

9. Takeuchi H, Miyata H, Gotoh M, et al. A risk model for esophagectomy using data of 5354 patients included in a Japanese nationwide web-based database. Ann Surg 2014;260:259-66.

10. Booka E, Takeuchi H, Suda K, et al. Meta-analysis of the impact of postoperative complications on survival after oesophagectomy for cancer. BJS Open 2018;2:276-84.

11. Hanna JM, Erhunmwunsee L, Berry M, et al. The prognostic importance of the number of dissected lymph nodes after induction chemoradiotherapy for esophageal cancer. Ann Thorac Surg 2015;99:265-9.

12. Sachdev G, Napolitano LM. Postoperative pulmonary complications: pneumonia and acute respiratory failure. Surg Clin North Am 2012;92:321-44, ix.

13. Park SY, Lee HS, Jang HJ, et al. Efficacy of intraoperative, single-bolus corticosteroid administration to prevent postoperative acute respiratory failure after oesophageal cancer surgery. Interact Cardiovasc Thorac Surg 2012;15:639-43.

14. Ferguson MK, Celauro AD, Prachand V. Prediction of major pulmonary complications after esophagectomy. Ann Thorac Surg 2011;91:1494-500; discussion 1500-1. 